\title{
INDEX OF VOLUME 51
}

Subjects:

\section{INDEX OF ABSTRACTS ${ }^{1}$}

Algebra and Theory of Numbers, 58, 221, 364, 517, 655, 874.

Analysis, 61, 223, 366, 518, 657, 877.

Applied Mathematics, 64, 225, 522, 661, 883.

Ergodic Theory, 68.

Geometry, 68, 225, 369, 523, 662, 884.

Logic and Foundations, 665, 885.

Statistics and Probability, 69, 226, 371, 665, 886.

Topology, 71, 226, 371, 525, 666, 887.

Authors:

Agnew, R. P., 33 (50; 823), 33 (50; 823), 496 (366), 839 (518), 839 (877), (877);

Ambrose, W., 838 (874); Arens, R. F., 23 (50; 827), 839 (525); Aroian, L. A., 23 (50; 827).

Baer, R., 839 (874), 839 (874), 839 (874), 839 (875), 839 (875), 839 (886);

Barankin, E. W., 354 (221); Barlaz, J., 839 (877); Beaumont, R. A., 39 (50; 821);

Beckenbach, E. F., 33 (50; 823), 39 (61), (657); Becker, H. W., 39 (58), 39 (58);

Bell, P. O., (523), (662); Bergman, S., 23 (50; 825), 838 (661), 839 (657); Bernstein, F., 32 (68), 354 (223); Bing, R. H., 840 (525), 840 (666), 840 (666), 840 (887); Birkhoff, G. 354 (221), 840 (665); Blumenthal, L. M., 33 (71), 840 (523), 840 (523); Boas, R. P., 23 (50; 824), 496 (367), 837 (878); Bochner, S., 840 (525); Bourgin, D. G., (887); Brauer, A. T., 840 (655); Brauer, R., 840 (517), 840 (875), (875); Brown, F. L., 840 (655); Browne, E. T., 840 (517); Bruck, R. H., 32 (50; 821), 33 (50; 821), 33 (59).

Cameron, R. H., 837 (518), 840 (518); Chern, S. S., 834, 840 (523), 840 (524); Civin, P., (878); Cohen, I. S., 838 (875), 838 (876); Copeland, A. H., 840 (655); Court, N. A., 838 (663); Coxeter, H. S. M., (884), (884), (884).

Day, M. M., 838 (885), 840 (884); DeBaggis, H. F., 496 (370), 840 (524); DeCicco, J., 23 (68), 355 (226), 840 (663), 841 (664); Díaz, J. B., 838 (878); Dix, C. H., 39 (64); Doob, J. L., (886); Dresden, A., 838 (658); Duffin, R. J., 838 (883); Dunford, N., 838 (879), 840 (518).

Eilenberg, S., 834; Erdös, P., 23 (50; 669), 840 (655); Everett, C. J., 33 (59), 33 (59), 841 (656); Eves, H. W., 23 (50; 825), 33 (64), 354 (64).

Federer, H., 496 (518); Feller, W., 26; Fine, N. J., 33 (59); Foster, A. L., 23 (50; 822), 354 (221); Fox, R. H., 23 (71), 32 (71), 839 (526); Frank, E., 496 (519), 841 (658); Friedman, B., 838 (879); Fu, C. Y., 39 (64); Fullerton, R. E., 32 (61).

Garabedian, H. L., 354 (224); Garrison, G. N., 354 (221); Gottschalk, W. H., 839 (888), 841 (887); Greenstone, L., 838 (879); Grove, V. G., 32 (69); Gumbel, E. J., 355 (226); Gustin, W., (888).

Hallett, E., 24 (50; 827); Halmos, P. R., 32 (68); Herzog, F., (519); Hill, J. D., 841 (520), (519); Hille, E., 23 (62), 839 (880), 841 (879); Hillman, A. P., 355 (60), 496 (364), 496 (364), 841 (517), 841 (520); Hollcroft, T. R., 33 (69); Hsiung, C. C., $23(50 ; 676), 33$ (69), Hua, L. K., 23 (50; 822), 23 (50; 822), 496 (369), 496 (369); Hughes, H. K., 32 (62); Hurewicz, W., 834.

Ingersoll, B. M., 23 (50; 824); Ingram, W. H., 841 (880).

Jackson, D., 355 (224); Jackson, S. B., 496 (225); Jacobson, N., 23 (50; 822), 24

${ }^{1}$ Numbers within parentheses refer to the page numbers for abstracts, and those outside parentheses refer to the pages for titles as listed in reports of meetings. 
(60); James, G., 493 (367); Jeffery, R. L., 24 (50; 669); Jehle, H., 838 (661); Johnson, R. E., 497 (222); Jonsson, B., 493 (364), 838 (656), 841 (656).

Kac, M., 355 (70), 841 (886); Kalisch, G. K., 497 (365); Kaplansky, I., 355 (60), 497 (365), 497 (365), 497 (371), 838 (875), 841 (365); Kasner, E., 23 (69), 355 (226), 841 (663), 841 (664), 841 (664); Kelly, P. J., 39 (50; 828); Kiokemeister, F., 33 (60), 33 (60); Kohn, W., 33 (65).

Lasley, J. W., 841 (664), 841 (664); Lehmer, D. H., 493 (367); Levitzki, J., 24 (50; 823), 841 (876); Livingood, J. N. B., 497 (222); Lonseth, A. T., 32 (70), 33 (70), 834; Loo, C. T., 33 (62), 33 (62); Lorch, E. R., 494 (224); Lowan, A. N., 33 (65).

McCoy, N. H., 497 (365); McLemore, Mrs. E. W., 39 (64); Marden, M., 497 (367); Martin, W. T., 837 (518); Meder, A. E., 24 (50; 827); Menger, K., 497 (370), 497 (370); Milgram, A. N., 841 (657); Miller, D. S., 24 (50; 669); Min, S. H., 23 (50; 822); Mitchell, J. M., 841 (658); Montgomery, D., 840 (525), 841 (526), 841 (888), (888); Moore, C. N., 842 (520); Moore, R. L., 355 (371); Mordell, L. J., 497 (517); Morgan, K. A., 493 (366); Moursund, A. F., 842 (659); Munroe, M. E., 842 (659); Murray, F. J., 355 (66), 355 (66), 838 (883).

Nelson, N. D., 842 (885); von Neumann, J., 26, 843 (660); Neyman, J., 493; Niven, I., 839 (876).

Olmsted, J. M. H., 842 (657); Opatowski, I., 34 (66), 842 (665, 1001), (886); Overholtzer, G., 39 (50; 665); Oxtoby, J. C., 839 (666).

Pall, G., 22, 842 (657); Parker, W. V., 842 (876); Pettit, H. P., 842 (665), 842 (885), 842 (885); Pollard, H., 23 (50; 824), 355 (225); Polya, G., 493, 493 (520); Poor, V. C., 497 (521), 842 (521); Pounder, J. R., 24 (50; 826); Purcell, E. J., 39 (69).

Rademacher, H. A., 834, 838 (880); Rad6, T., 842 (880); Reid, W. T., 33 (62), 842 (881), 842 (881); Richardson, M., 842 (666); Rickart, C. E., 838 (881); Rider, P. R., 842 (225); Robbins, H. E., 842 (881); Robertson, M. S., 839 (882), 842 (882); Robinson, R. M., 493 (368), 842 (665); Roettinger, I., 34 (67); Roever, W. H., 32 (67); Rosenbloom, P. C., 838 (882); Rosenbluth, A., 838 (662); Rosenthall, E., 842 (877).

Salem, R., 24 (50; 824), 842 (521), 843 (521), 843 (659); Salzer, H. E., 33 (65), 355 (67), 843 (522, 1001), 843 (522), 843 (662), 843 (883); Samelson, H., (888); Satterthwaite, F. E., 355 (366); Schatten, R., 840 (518), 839 (659); Scheffé, H., 39 (71); Scherk, P., 843 (370); Schoenberg, I. J., 24 (50; 825), 24 (50; 826), 834; Schweitzer, A. R., 34 (63), 497 (368), 843 (524), 843 (525); Seidenberg, A., 838 (876); Sheffer, I. M., 843 (521); Sherman, S., 34 (61); Smiley, M. F., 355 (222); Snapper, E., 355 (222); Snyder, W. S., 32 (63); Sorgenfrey, R. H., 355 (226); Stephens, C. F., 843 (660); Sternberg, W. J., 355 (223); Stoker, J. J., 23 (68); Stone, A. H., 24 (50; 828); Szász, O., 23 (50; 825), 497 (368), 838 (522); Szegö, G., 39, 493 (520).

Tarski, A., 838 (656), 841 (656); Trjitzinsky, W. J., 32 (63), 838 (660), 843 (522); Truesdell, C. A., 355 (225), 838 (883); Tuan, H. F., 840 (517).

Ulam, S. M., 33 (59), 843 (660).

Vickery, C. W., 843 (660).

Wall, H. S., 32 (50; 672), 497 (223), 843 (660), 843 (661); Wallace, A. D., 839 (667), 843 (526), 843 (526), 843 (527), 843 (667); Wang, F. T., 497 (369), 497 (369); Weinstein, A., $24(50 ; 826)$; White, P. A., $33(50 ; 828), 355$ (226); Whitehead, G. W., 24 (50; 828), 33 (60); Whyburn, G. T., 355 (371), 355 (371), 839 (667), 843 (667); Wiener, N., 838 (662); Wilkins, J. E., 23 (50; 826), 497 (366); Wolf, F., 39.

Young, G. S., 839 (667).

Zimmerberg, H. J., 837 (369); Zygmund, A., 34 (63), 842 (521), 843 (521), 843 (659). 


\section{INDEX OF REPORTS OF MEETINGS AND MISCELLANEOUS ARTICLES}

Hollcroft, T. R. Reports of meetings of the American Mathematical Society: October meeting in New York, 22; Annual meeting of the Society, 25; Summer meeting in New Brunswick, 833.

Kline, J. R. Reports of the meetings of the Council of the Society: New York City, February 24, 1945, 351; New York City, A pril 28, 1945, 494.

Michal, A. D. Report of meeting of the American Mathematical Society: November meeting in Los Angeles, 39.

National Research Council. Predoctoral fellowships in the natural sciences, 854.

O'Connor, R. E. Canadian mathematical congress, 856.

Schaeffer, A. C. Report of meeting of the American Mathematical Society: April meeting in Stanford University, 493.

Simons, L. G. David Eugene Smith-In Memoriam, 40.

Smith, D. E. See Simons, L. G.

War Policy Committee. Universal military service in peace time, 844.

\section{INDEX OF BOOK REVIEWS}

Agnew, R. P. See McShane, E. J. See Hyslop, J. M.

Albert, A. A. See Artin, E.

Artin, E. Galois theory. A. A. Albert, 359.

Artin, E., Nesbitt, C. J., and Thrall, R. M. Rings with minimum condition. O. F. G. Schilling, 510.

Bennett, A. A. See Quine, W. V. O.

Burgess, R. W. See Wilks, S. S.

Chandrasekhar, S. Principles of stellar dynamics. D. C. Lewis, 504.

Church, A. Introduction to mathematical logic. Part I. O. Frink, 863.

Copeland, A. H. See von Neumann, J.

Cross, P. C. See Margenau, H.

Frink, O. See Church, A.

Hardy, G. H., and Rogosinski, W. W. Fourier series. M. H. Heins, 212.

Heins, M. H. See Hardy, G. H.

Herzberger, M. See Luneberg, R. K.

Hotelling, H. See Kendall, M. G.

Hyslop, J. M. Infinite series. R. P. Agnew, 356.

Kendall, M. G. The advanced theory of statistics. Vol. 1. H. Hotelling, 214.

Lewis, D. C. See Chandrasekhar, S.

Luneberg, R. K. Mathematical theory of optics. M. Herzberger and R. v. Mises, 865.

McShane, E. J. Integration. R. P. Agnew, 51.

Margenau, H., and Murphy, G. M. The mathematics of physics and chemistry. P. C. Cross, 508.

Mises, R. v. See Luneberg, R. K.

Moore, C. N. See Watson, G. N.

Morehead, J. C., and Morehead, J. C., Jr. A handbook of perspective drawing. W. H. Roever, 216.

Morehead, J. C., Jr., See Morehead, J. C.

Morgenstern, O. See von Neumann, J.

Murphy, G. M. See Margenau, H. 
Nesbitt, C. J. See Artin, E.

von Neumann, J., and Morgenstern, $\mathrm{O}$. Theory of games and economic behavior. A. H. Copeland, 498.

Quine, W. V. O. O sentido da nova lógica. A. A. Bennett, 509.

Roever, W. H. See Morehead, J. C.

Rogosinski, W. W. See Hardy, G. H.

Schilling, O. F. G. See Artin, E.

Shohat, J. A., and Tamarkin, J. D. The problem of moments. D. V. Widder, 860.

Tamarkin, J. D. See Shohat, J. A.

Thrall, R. M. See Artin, E.

Watson, G. N. A treatise on the theory of Bessel functions. C. N. Moore, 649.

Widder, D. V. See Shohat, J. A.

Wilks, S. S. Mathematical statistics. R. W. Burgess, 647.

Williams, A. O., Jr., See Work Projects Administration.

Work Projects Administration. Miscellaneous physical tables. Planck's radiation functions and electronic functions. A. O. Williams, 358.

\section{INDEX OF ADDRESSES}

Artin, E., and Whaples, G. Axiomatic characterization of fields by the product formula for valuations, 469 .

Bateman, H. The control of an elastic fluid, 601, 1001.

Feller, W. The fundamental limit theorems in probability, 800.

Hyers, D. H. Linear topological spaces, 1, 1001.

MacDuffee, C. C. On the composition of algebraic forms of higher degree, 198.

Pall, G. The arithmetical invariants of quadratic forms, 185.

Stewart, H. J. Hydrodynamic problems arising from the investigation of the transverse circulation in the atmosphere, 781.

Szegö, G. On the capacity of a condenser, 325.

Whaples, G. See Artin, E.

\section{INDEX OF RESEARCH PAPERS}

Agnew, R. P. A genesis for Cesdro methods, 90.

- Spans in Lebesgue and uniform spaces of translations of step functions, 229.

Anning, N. H., and Erdös, P. Integral distances, 598.

Artin, E. See Index of Addresses.

Baer, R. Null systems in projective space, 903.

Barankin, E. W. Bounds for the characteristic roots of a matrix, 767.

Barker, C. B. Proof that the Mersenne number $M_{167}$ is composite, 389.

Bateman, H. See Index of Addresses.

Beaumont, R. A. Groups with isomorphic proper subgroups, 381.

Beckenbach, E. F. Concerning the definition of harmonic functions, 240.

- On a characteristic property of linear functions, 923.

Bell, P. O. Metric properties of a class of quadratic differential forms, 563.

Bergman, S. A class of nonlinear partial differential equations and their properties, 545.

Bing, R. H. Collections filling up a simple plane web, 674.

- Generalizations of two theorems of Janiszewski, 954.

Blackwell, D. The existence of anormal chains, 465.

Boas, R. P. A differential inequality, 95.

Bourgin, D. G. Quadratic forms, 907.

Brauer, R. A note on systems of homogeneous algebraic equations, 749. 
Brauer, R., and Tuan, H. F. On simple groups of finite order. I, 756.

Busemann, H., and Feller, W. Regularity properties of a certain class of surfaces, 583.

Cameron, R. H., and Martin, W. T. Evaluation of various Wiener integrals by use of certain Sturm-Liouville differential equations, 73.

Chern, S. S. On Riemannian manifolds of four dimensions, 964.

DeCicco, J. The pseudo-angle in space of $2 n$ dimensions, 162. See Kasner, E.

Duffin, R. J. Representation of Fourier integrals as sums. I, 447.

Erdös, P. On the least primitive root of a prime $p, 131$.

- Some remarks on Euler's $\phi$ function and some related problems, 540.

- Some remarks on the measurability of certain sets, 728.

- On a lemma of Littlewood and Offord, 898.

Integral distances, 996.

- See Anning, N. H.

Erdös, P., and Niven, I. On certain variations of the harmonic series, 433.

Erdös, P., and Stone, A. H. Some remarks on almost periodic transformations, 126.

Everett, C. J. The basis theorem for vector spaces over rings, 531.

Feller, W. See Busemann, H.; Index of Addresses.

Fox, R. H. On topologies for function spaces, 429.

Goodman, R. E. On the Bloch-Landau constant for schlicht functions, 234.

Grove, V. G. Quadrics associated with a curve on a surface, 281.

Hadamard, J. Correction to "A known problem of geometry and its cases of indetermination," 1001.

Hall, M. An existence theorem for Latin squares, 387.

Hartman, P. Remark on Taylor's formula, 731.

Hsiung, C. C. Some invariants of certain pairs of hypersurfaces, 572.

Hsü, H. T. The strong summability of double Fourier series, 700.

Hsu, L. C. S. A combinatorial formula with some applications, 106.

Hua, L. K. A remark on a result due to Blichfeldt, 537.

Hughes, H. K. The asymptotic developments of a class of entire functions, 456.

Hyers, D. H. See Index of Addresses.

Hyers, D. H., and Ulam, S. M. On approximate isometries, 288.

Jonah, H. F. S. Congruences connected with the solution of a certain diophantine equation, 137.

- Development of certain quadratic functional equations, 147.

Kaplansky, I. A note on groups without isomorphic subgroups, 529.

Kaplansky, I., and Pollard, H. Note on the preceding paper, 437.

Kasner, E., and DeCicco, J. Bi-isothermal systems, 169.

A new characteristic property of minimal surfaces, 692.

Kelly, P. J. On isometries of square sets, 960.

Kiang, T. The manifolds of linear elements of an n-sphere, 417.

Knebelman, M. S. On the equations of motion in a Riemann space, 682.

Kosambi, D. D. Parallelism in the tensor analysis of partial differential equations, 293.

Lagerstrom, P. A proof of a theorem on commutative matrices, 535.

See McMillan, B.

Lane, R. E. The convergence and values of periodic continued fractions, 246.

Levitzki, J. On three problems concerning nil-rings, 913.

McMillan, B., and Lagerstrom, P. Extension of a theorem of Bochner on expressing functionals as Riemann integrals, 251.

MacDuffee, C. C. See Index of Addresses. 
MacQueen, M. L. A note on hypergeodesics and canonical lines, 400.

Marden, M. A note on the zeros of the sections of a partial fraction, 935.

Martin, W. T. See Cameron, R. H.

von Mezynski, I. M. Projective description of some plane sextic curves derived from conics as base curves, 175.

Mises, R. v. On Saint Venant's principle, 555.

Montgomery, D. Measure preserving homeomorphisms at fixed points, 949.

Motzkin, T. A 5 curve theorem generalizing the theorem of Carnot, 972.

- The hypersurface cross ratio, 976.

The pentagon in the projective plane, with a comment on Napier's rule, 985.

Niven, I. See Erdös, P.

Olmsted, J. M. H. Transfinite rationals, 776.

Overholtzer, G. A new application of the Schur derivate, 313.

Pall, G. Note on factorization in a quadratic field, 771.

Hermitian quadratic forms in a quasi-field, 889. See Index of Addresses.

Pinney, E. A class of integral equations which generalize Abel's equation, 259.

Pollard, H. See Kaplansky, I.

Poor, V. C. On the Hamilton differential, 945.

Rainville, E. D. A relation between Jacobi and Laguerre polynomials, 266. Notes on Legendre polynomials, 268.

The contiguous function relations for ${ }_{p} F_{q}$ with applications to Bateman's $J_{n}^{u, v}$ and Rice's $H_{n}(\zeta, p, v), 714$

Reiner, I. On genera of binary quadratic forms, 909.

Reissner, E. Solution of a class of singular integral equations, 920.

Riordan, J. Permutations without 3-sequences, 745.

Robertson, M. S. The coefficients of univalent functions, 733.

Rosenblatt, A. On the growth of the solutions of ordinary differential equations, 723.

Salzer, H. E. Note on interpolation for a function of several variables, 279.

Santalo, L. A. Note on convex curves on the hyperbolic plane, 405.

Schafer, R. D. On a construction for division algebras of order 16, 532.

Schilling, O. F. G. On a special class of abelian functions, 133.

- Noncommutative valuations, 297.

Segre, B. Arithmetic upon an algebraic surface, 152.

Sheffer, I. M. Note on Appell polynomials, 739.

Smiley, M. F. A remark on metric Boolean rings, 378.

Smith, J. C. Asymptotic distribution of sums of Rademacher functions, 941.

Springer, C. E. Union curves and union curvature, 686.

_ Rectilinear congruences whose developables intersect a surface in its lines of curvature, 990.

Sternberg, W. J. A new solution for linear difference equations, 462.

Stewart, H. J. See Index of Addresses.

Stone, A. H. See Erdös, P.

Szegö, G. See Index of Addresses.

Thomas, T. Y. Algebraic determination of the second fundamental form of a surface by its mean curvature, 390.

Tuan, H. F. A note on the replicas of nilpotent matrices, 305.

- See Brauer, R.

Ulam, S. M. See Hyers, D. H. 
Wall, H. S. Note on the expansion of a power series into a continued fraction, 97, 1002. Note on a certain continued fraction, 930.

Wallace, A. D. A fixed-point theorem, 413.

Dimensional types, 679.

Wehausen, J. V. Transformations in metric spaces and ordinary differential equations, 113.

Weil, A. A correction to my book on topological groups, 272.

Wernick, W. Distributive properties of set operators, 120.

Whaples, G. See Index of Addresses.

Whiteman, A. L. A note on Kloosterman sums, 373.

Williamson, J. Note on the equivalence of nonsingular pencils of Hermitian matrices, 894. Wong, Y. C. A note on the first normal space of $a V_{m}$ in an $R_{n}, 997$.

Youngs, J. W. T. On surfaces of class $K_{1}, 669$.

Zygmund, A. On the degree of approximation of functions by Fejêr means, 274. Proof of a theorem of Littlewood and Paley, 439. 